\title{
Variations on Reservoir Parameters of Oil Shale Deposits under Periodic Freeze-Thaw Cycles: Laboratory Tests
}

\author{
Rui-heng Li, ${ }^{1}$ Zhong-guang Sun $\mathbb{D}^{1,2,3}$ Jiang-fu He $\mathbb{D}^{1},{ }^{1}$ Zhi-wei Liao $\mathbb{D}^{1}{ }^{1}$ Lei Li, ${ }^{1,3}$ \\ and Fang Qian ${ }^{4}$ \\ ${ }^{1}$ Chongqing University, State Key Laboratory of Coal Mine Disaster Dynamics and Control, Chongqing 400030, China \\ ${ }^{2}$ State Key Laboratory of Gas Disaster Detecting, Preventing and Emergency Controlling, Chongqing 400037, China \\ ${ }^{3}$ China Coal Technology and Engineering Group Chongqing Research Institute, Chongqing 400039, China \\ ${ }^{4}$ College of Construction Engineering, Jilin University, Changchun 130021, China
}

Correspondence should be addressed to Jiang-fu He; hejf2016@cqu.edu.cn

Received 1 August 2021; Accepted 30 October 2021; Published 16 November 2021

Academic Editor: Zhengyang Song

Copyright (c) 2021 Rui-heng Li et al. This is an open access article distributed under the Creative Commons Attribution License, which permits unrestricted use, distribution, and reproduction in any medium, provided the original work is properly cited.

As one of the most important unconventional hydrocarbon resources, the oil shale has been extracted with a frozen wall to successfully increase the shale oil production and reduce environmental pollution, which results from the harmful liquids in the in situ conversion processing of oil shale. Thereby, the strength and permeability of the frozen wall are extremely critical to reduce the harmful chemicals leaching into the groundwater. However, the permeability and strength of the frozen wall can be influenced by periodic freeze-thaw cycles. In order to investigate the damage and deterioration characteristics of oil shale samples after various periodic freeze-thaw cycles, the oil shale samples were periodically frozen and thawed as many as 48 times, after which the sample mass, stress-strain, freeze-thaw coefficient, uniaxial compressive strength, elastic modulus, and longitudinal wave velocity of the oil shale samples were separately measured. According to the measured results, the number of freeze-thaw cycles greatly influenced the physical and mechanical properties of oil shale samples. The uniaxial compressive strength and elastic modulus of the oil shale samples were changed with maximum variation rates of $64 \%$ and $65 \%$, respectively. Meanwhile, the freeze-thaw coefficient of measured oil shale samples exponentially decreased with the increased number of freeze-thaw cycles, whereas the longitudinal wave velocity of tested samples ranged from $1602 \mathrm{~m} / \mathrm{s}$ to $2464 \mathrm{~m} / \mathrm{s}$ as a result of the new micropores inside the oil shale sample. Research results have enormous significance to the efficient and safe in situ exploitation of oil shale deposits.

\section{Introduction}

Oil shale is considered an important unconventional hydrocarbon resource, and its worldwide reservoir volume is huge. According to the latest report of the World Energy Council [1], the converted reserves of oil shale resources into shale oil reaches up to $4.8 \times 10^{12} \mathrm{bbl}$ throughout the world, which is 4 times as much as the world' $s$ oil resources. It can be confirmed that there are more than 300 shale deposits distributed in 40 countries, though the most abundant oil shale resources are located in the United States [2]. With the increasing price of the crude oil, the new energy resources, such as oil shale, have received further attention due to their tremendous prospects for the production and utilization $[3,4]$. Therefore, various production technologies of the shale oil have been proposed, such as true in situ (TIS) and modified in situ (MIS) for the conversion of oil shale [5]. In addition, the in situ conversion and restoration of shale oil are mainly accomplished by means of heat and chemistry activation, which intensively change the underground environment and reservoir property of the oil shale [6].

In shell' $s$ in situ retorting and conversion process, the kerogen of shale oil is thermally decomposed and converted into shale oil gas, which will be collected and separated above ground [7, 8]. However, the uncollected liquids in the spent shale or the vapour produced during in situ 

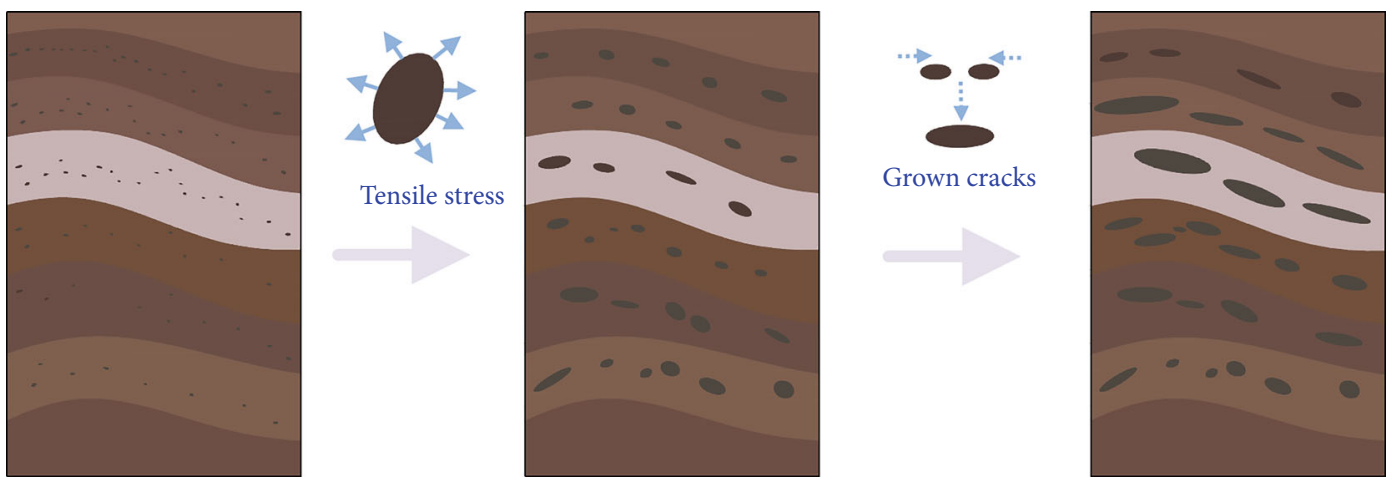

FIGURE 1: Schematic diagram of periodic freeze-thaw action process in oil shale samples.
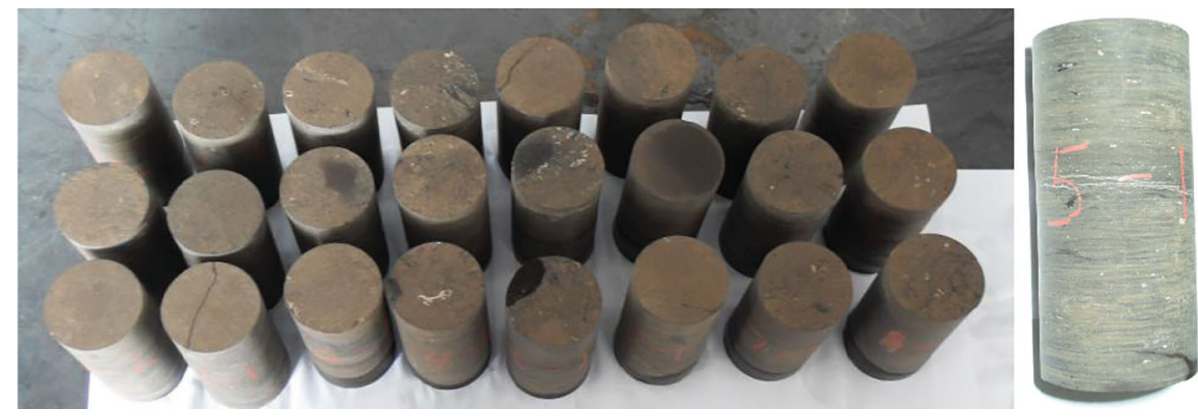

FIgURE 2: The tested oil shale samples with a diameter of $35 \mathrm{~mm}$.

TABLE 1: Physical parameters of the tested oil shale samples.

\begin{tabular}{lcc}
\hline Dry density $\rho\left(\mathrm{g} / \mathrm{cm}^{3}\right)$ & $\begin{array}{c}\text { Natural moisture } \\
\text { content }(\%)\end{array}$ & Porosity (\%) \\
\hline 1.40 & 5.5490 & 1.7972 \\
\hline
\end{tabular}

retorting may leach into groundwater; thereby, a frozen wall acts as an underground barrier around the oil shale site [9]. Besides, the freezing technology was applied to form a water-proof structure during the in situ production of underground energy [10]. In order to prevent groundwater from entering the oil shale site and prevent the harmful liquids produced by the in situ retorting from leaching out at the site, the frozen wall has been successfully utilized for the in situ conversion processing of oil shale $[11,12]$. Initially, the targeted oil shale reservoir is enclosed with a cluster of freezing boreholes, which facilitates the rapid formation of underground frozen wall with expected coolant temperature of minus $42.8^{\circ} \mathrm{C}$. Due to the permeability and strength of the frozen wall are determined by the physical and mechanical properties of oil shale deposits, the potential production capacity of shale oil may also be reduced when the conditions of the frozen wall, such as temperature, stress, and confining pressure, are changed. Once the strength and permeability of frozen wall have been weakened by freezing-thawing conditions, the underground water will be directly polluted, and the production efficiency will be subsequently reduced. In addition, the deformation and failure of frozen wall eventually leads to the potential pipe breakages, which dramatically increase the production cost of shale oil $[13,14]$. Thereby, the influence of freeze-thaw condition on the quality of frozen wall is extremely crucial for improving the exploitation of oil shale reservoir [15].

In previous studies, great advancements about the effects of periodic freeze-thaw conditions on variations of the mechanical and physical properties of other rocks have been made in recent years [16]. [17] from Spain conducted series of freeze-thaw experiments on various types of granites for 56 cycles with time intervals of $4 \mathrm{~h}, 8 \mathrm{~h}$, and $12 \mathrm{~h}$ while the temperature was ranging from $12^{\circ} \mathrm{C}$ to $20^{\circ} \mathrm{C}$. Subsequently, the ultrasonic wave velocity of granite samples was tested after every freeze-thaw cycle. The test results showed that the ultrasonic velocity of granite samples decreases with the lithology and freeze-thaw cycles, which result from the increased number of pores and microcracks caused by the freeze-thaw action. Yavuz [18] also found that the hardness, comprehensive strength, and P-wave velocity of andesite samples reduced after 10 freeze-thaw cycles and 50 thermal shock cycles, whereas the porosity and water absorption rate of the measured samples increased.

The rock mechanical properties under periodic freezethaw cycles were researched by Yang and Zhang, and the influence of freezing temperatures and freezing speed on the deterioration characteristics of rocks was obtained by using CT scanning equipment [19-21]. Besides, the temperature variation of frozen soil wall and the evolution characteristics of the specific heat capacity are analyzed by Yang et al. [22]. Wu Gang [23] separately tested the deterioration characteristics of saturated and dry rock samples with 60 freeze-thaw cycles, and the ultrasonic longitudinal wave and shear wave velocities were measured by the ultrasonic tester. Working with granite samples obtained from Jilin, 


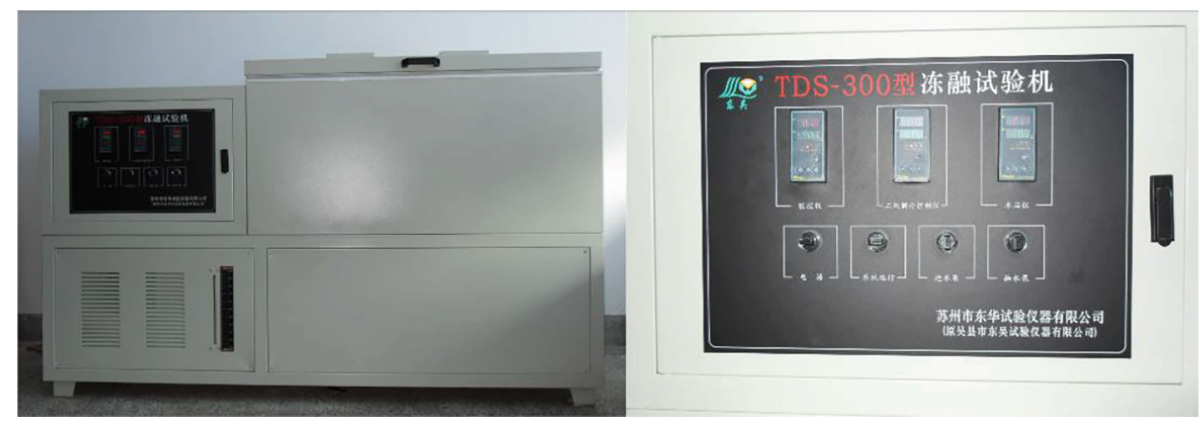

FIGURE 3: Experimental apparatus of TDS-300 periodic freeze-thaw cycles.

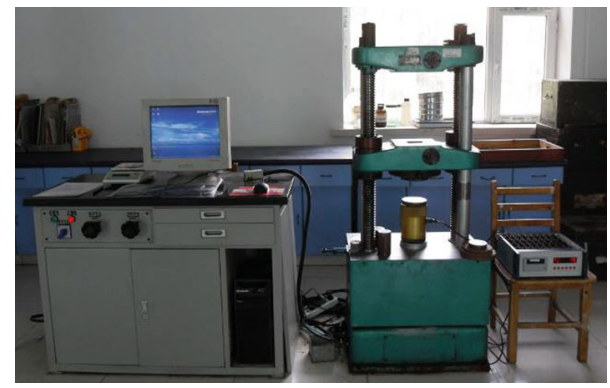

Figure 4: DNS100 microcomputer controlled electronic test machine.

China, Liu [24] conducted freeze-thaw experiments for 20 cycles under the condition of local minimum temperature. The test results showed that low-temperature freeze-thaw cycles have no obvious effect on the quality of granite, whereas these cycles have a great impact on the strength, stiffness, and Poisson's ratio of the tested samples. In addition, Bellanger [25] analyzed the calculation method of tunnel frost heaving force corresponding to the physical and mechanical properties of rock samples. Overall, several effective methods for controlling the freezing deterioration of soft rock have been proposed, including changing the physical and mechanical properties of the rock, extruding the pore water from the frozen area, and increasing the internal temperature of the tunnel [26].

In present studies, the influence of periodic freeze-thaw cycles on the deterioration characteristics of undermined oil shale is adequately analyzed according to the changes in physical and mechanical properties of rock samples. Studies on the physical and mechanical characteristics of oil shale samples will facilitate the development and utilization of oil shale resources. In addition, the oil shale samples recovered from Huadian Oil Field were utilized to measure the physical and mechanical properties of the tested samples. The freeze-thaw testing machine and mechanical testing machine were used to assess the damage and deterioration characteristics of oil shale samples under conditions of periodic freeze-thaw cycles, and the influence of periodic freeze -thaw cycle on the variation of mechanical and physical properties was investigated. The findings will contribute to the comprehensive study of oil shale samples, especially for the exploitation and production of oil shale deposits.

\section{Mechanism of the Periodic Freeze- Thaw Cycle}

Freeze-thaw cycles refer to the periodic freezing or thawing of rock and soil while the temperature falls below zero or rises above zero, which belongs to the physical and geological process phenomenon. Under minus temperature condition, water in the fractures of rock and soil will be frozen and expanded; thus, excessive pressure produced by ice particles will be accumulated inside the rock fracture. However, the frozen ice existed inside the fractures will be melted while the temperature rises, and the water droplets as well as moisture move along the pores or capillary pathway of the structure surface to the internal structure. Hence, the pressure on two walls of the rock fracture was dramatically decreased, and two walls between rock fractures push back to the center. Moisture in the structure surface and internal fractures will be alternately frozen and melted, which is known as periodic freeze-thaw cycle. As shown in Figure 1, during the process of periodic freeze-thaw cycle, fractures inside the rock will be expanded and grown in quantity; accordingly, the stones are separated by rock particles [27].

Freeze-thaw deterioration of rocks is an integrated process derived from the physical, chemical, and mechanical phenomena. It is a complicated process coupling with a multifield of temperature, water, and force, especially the energy transfer, phase change, and migration of water [28]. The essence of freeze-thaw damage and deterioration is that the compositions of rock, such as water, ice, and mineral, have different thermal physical properties [29]. Due to different crystalline orientations have different thermoelastic properties, as well as different shrink and expansion ratios of various mineral particles, shrinkages and expansions across the grain boundary are unbalanced, which applies a gravity force between mineral grains and micropore. The weakly cemented rock particles will be destroyed by such internal stress and cause partial damage and deterioration inside the rock matrix. While the temperature dropping to the freezing point, water transforms from liquid to solid, and this process will generate inflation tensile stress, which will lead to the damage of some weak rock particles. When the temperature rises, pore fissure water in the rock melts, freezing stress releases, moisture migrates, and fracture in local damage area interconnects, eventually aggravating this damage. With the increase of periodic freeze-thaw cycle, internal stress 
TABLE 2: State of each group of samples.

\begin{tabular}{lcccccccc}
\hline Group & Group 1 & Group 2 & Group 3 & Group 4 & Group 5 & Group 6 & Group 7 & Group8 \\
\hline Hydrous conditions & Dry & Saturated & Saturated & Saturated & Saturated & Saturated & Saturated & Saturated \\
Cycle times & 0 & 0 & 2 times & 4 times & 8 times & 16 times & 24 times & 48 times \\
\hline
\end{tabular}

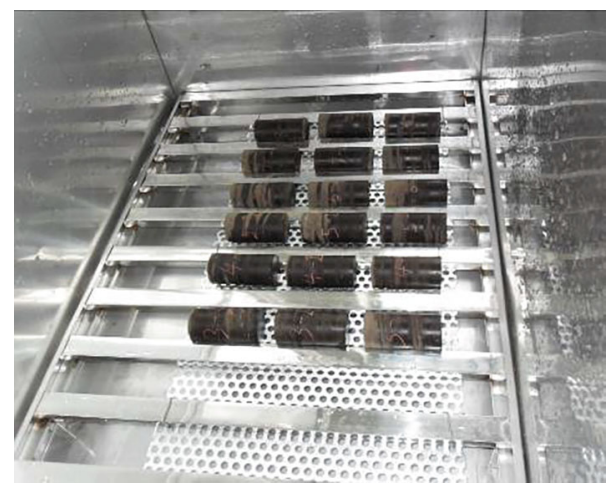

FIgURE 5: Samples in the periodic freeze-thaw experimental apparatus.

alternately acts on the skeleton of rock mass with the external temperature circulation, which causes irreversible deterioration inside the rock matrix.

According to Lemaitre' s brittle damage model, the deterioration characteristic of oil shale sample can be specified by the uniaxial compression strain, as shown in formula (1):

$$
D=\left(\frac{\varepsilon}{\varepsilon_{r}}\right)^{k}
$$

According to the relationship between stress and strain obtained from uniaxial compression, the stress can be expressed as

$$
\sigma=E(1-D) \varepsilon
$$

Thereby, the damage constitutive equation of oil shale samples can be presented as formula (3) after various freeze-thaw cycles:

$$
\sigma=E(n)\left[1-\left(\frac{\varepsilon}{\varepsilon_{r}}\right)^{k}\right] \varepsilon
$$

Besides,

$$
E(n)=E_{0}[1-D(n)]
$$

Eventually,

$$
\sigma=E_{0}[1-D(n)]\left[1-\left(\frac{\varepsilon}{\varepsilon_{r}}\right)^{k}\right] \varepsilon,
$$

where $D$ denotes the damage degree of oil shale, $n$ denotes the freeze-thaw cycles, $E$ denotes the elasticity modulus of raw oil shale, $E(n)$ denotes the elasticity modulus of frozen oil shale, $\varepsilon$ denotes the initial strain of oil shale sample, and $\varepsilon_{r}$ denotes the strain of frozen oil shale.

It can be indicated that the uniaxial compression strength of the oil shale sample is closely influenced by freeze-thaw cycles, which conversely changes the physical and mechanical properties of oil shale samples. Therefore, the variation of uniaxial compressive strength, mass, freeze-thaw coefficient, stress, and strain of tested oil shale samples will be discussed with various freeze-thaw cycles in the present research.

\section{Tests on the Oil Shale Samples with Periodic Freeze-Thaw Cycle}

3.1. Preparation of Tested Oil Shale Samples. The tested oil shale samples were recovered from Huadian Basin, Jilin Province, China. The dimension of all tested samples is $\varphi$ $50 \mathrm{~mm} \times 100 \mathrm{~mm}$, and the dry density of all samples is approximately $1.4 \mathrm{~g} / \mathrm{m}^{3}$. The reservoir depth of tested oil shale sample is $600 \mathrm{~m}$, and the seam deposition age in Huadian belongs to the Tertiary period of the Cenozoic [30]. Besides, the tested samples were prepared by drilling and coring in oil shale mass with a water drilling method in the laboratory. According to the requirements for thin samples, the height-diameter ratio of prepared samples was $2: 1$, which accords with the requirement for improving measurement errors. In present experiments, a total of 24 pieces of oil shale samples with good integrity were tested, and the tested samples were as shown in Figure 2.

Meanwhile, other specified physical parameters of the tested oil shale samples are as shown in Table 1. The dry density was tested by dehydrating for 48 hours in a drying oven, whereas the natural moisture content and porosity were simultaneously measured with a QKY-11 gassy porosity detector manufactured by Nantong Experimental Apparatus Company. The porosity of oil shale samples can be calculated based on the solid volume and physical volume of the tested samples. The solid volume is derived from the balance pressure of a standard curve.

3.2. Experimental Apparatus. The test apparatus with a specified cryogenic bath is termed as TDS-300 freeze-thaw cycle test machine, which was manufactured by Suzhou Donghua Test Instrument Co., Ltd., as shown in Figure 3. The minimum working temperature of the test machine is $-40^{\circ} \mathrm{C}$, and the periodic freeze-thaw cycle of the oil shale samples can be conducted by freezing in the test machine and thawing in the water. Once the freezing temperature of the tested sample is confirmed, the periodic freeze-thaw cycles of oil shale samples will be automatically completed without extra 


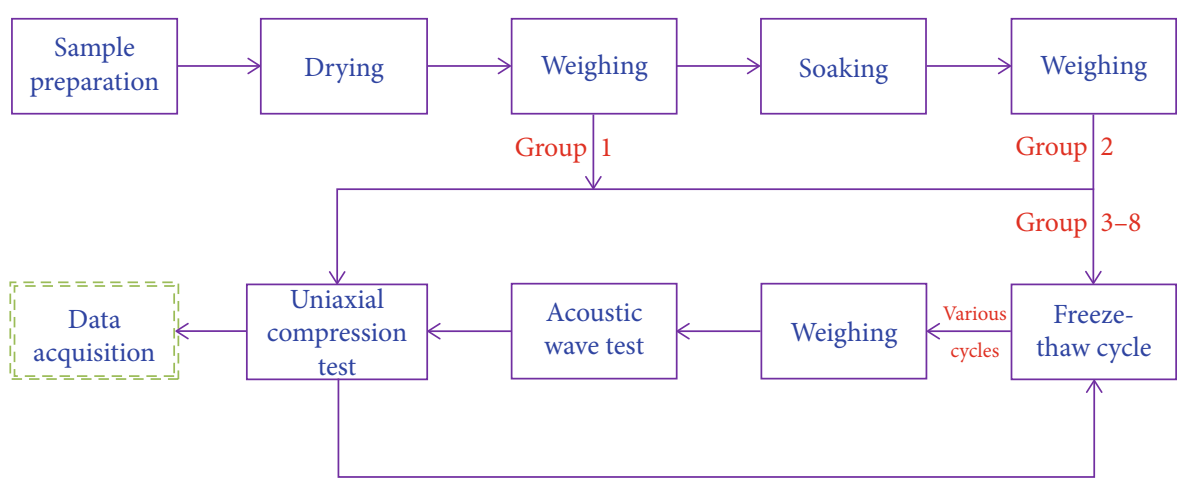

FIGURE 6: Flow diagram of the periodic freeze-thaw experiments.

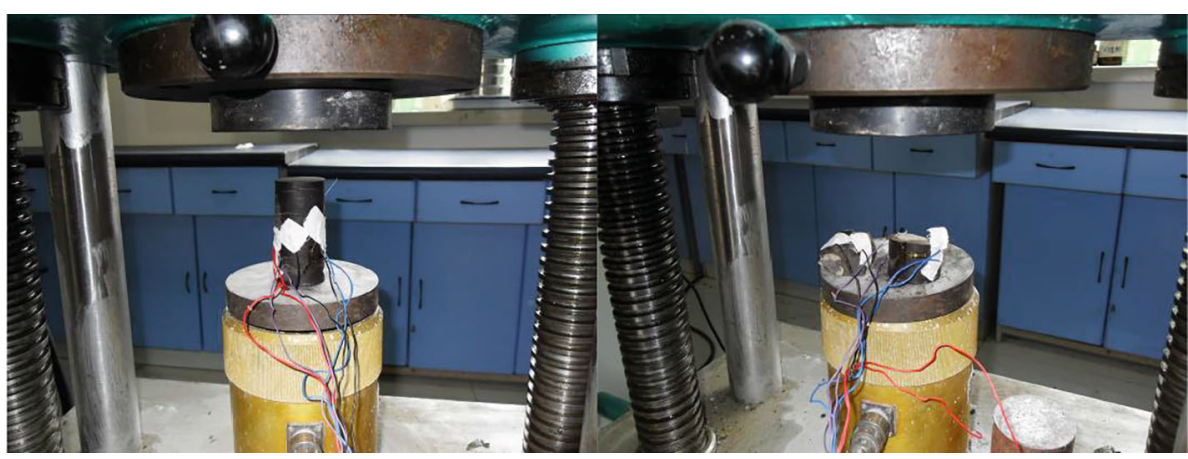

Figure 7: Test on the mechanical properties of the measured oil shale samples.

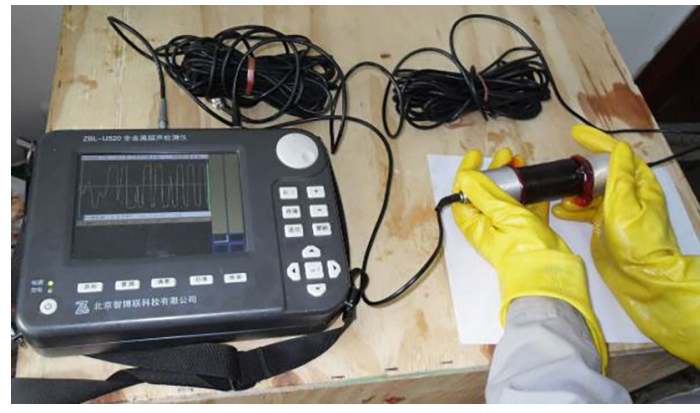

FIgURE 8: Ultrasonic detection on oil shale samples after periodic freeze-thaw cycles.

operations. Overall, relevant requirements of the standard measurement of periodic freeze-thaw cycles are qualified.

The mechanical and physical properties of the oil shale samples were measured with a DNS100 microcomputer, controlled by electronic universal testing machine, as shown in Figure 4. The universal testing machines are mainly used for testing the tensile, compression, bending, shear, peel, tear, and other mechanical properties for all types of metallic, nonmetallic, and composite materials. The maximum force, tensile strength, bending strength, compression strength, elastic modulus, breaking elongation, yield strength, and other parameters can be obtained. Meanwhile, the ZBL-U520 ultrasonic detector, electronic balance (tolerance of $0.0001 \mathrm{~g}$ ) accuracy, vernier caliper, and drying oven have been utilized in all experiments.
3.3. Experimental Methods and Proposals. According to the operation specification of conventional rock experiments under conditions of periodic freeze-thaw cycles in water conservancy and hydroelectric engineering (SL264-2001), all periodic freeze-thaw experiments were conducted with $-20^{\circ} \mathrm{C}$ freezing temperature and $20^{\circ} \mathrm{C}$ thawing temperature.

The experimental procedures were as follows: firstly, the oil shale samples were frozen for 4 hours in the test apparatus with a temperature of $-20^{\circ} \mathrm{C}$, then being thawed for 4 hours in the water at a temperature of $20^{\circ} \mathrm{C}$, namely, each freeze-thaw time step was 8 hours. There were 8 groups of oil shale samples in all freeze-thaw experiments, and each group included 3 samples. Six groups of samples were processed under conditions of periodic freeze-thaw cycles with 2, $4,8,16,24$, and 48 hours, separately. Before the periodic freeze-thaw experiments, all the oil shale samples were placed in the oven (temperature at $105^{\circ} \mathrm{C}$ ) for 48 hours, which is aimed at dehydrating all the samples to a constant weight (mass changes no greater than $0.1 \%$ in 24 hours). Then, the mass of each oil shale sample can be weighed and recorded. As shown in Table 2, totally, 2-8 groups of samples were continuously vacuumed for 4 hours until no air bubbles existed in the sample.

Subsequently, the oil shale sample was placed in distilled water for 48 hours until to be saturated; thus, the mass of each oil shale sample can also be weighed and recorded. The oil shale samples in group 1 and group 2 were prepared for the uniaxial compressive strength experiment, and the rest of the samples were placed in the freeze-thaw experimental apparatus for periodic freeze-thaw experiment, as 
TABLE 3: Mass changes of oil shale samples before and after periodic freeze-thaw cycles.

\begin{tabular}{|c|c|c|c|c|c|}
\hline $\begin{array}{l}\text { Freeze-thaw cycle } \\
\text { times (time) }\end{array}$ & Sample no. & Mass before freeze-thaw cycles (g) & Mass after freeze-thaw cycles (g) & $\begin{array}{l}\text { Rate of mass } \\
\text { change }(\%)\end{array}$ & $\begin{array}{c}\text { Average rate of } \\
\text { mass change }(\%)\end{array}$ \\
\hline \multirow{3}{*}{0} & OS-2-1 & 139.5024 & - & - & \multirow{3}{*}{-} \\
\hline & OS-2-2 & 147.6156 & - & - & \\
\hline & OS-2-3 & 138.8170 & - & - & \\
\hline \multirow{3}{*}{2} & OS-3-1 & 138.2813 & 141.5362 & 2.35 & \multirow{3}{*}{2.22} \\
\hline & OS-3-2 & 134.1621 & 136.6143 & 1.83 & \\
\hline & OS-3-3 & 145.2909 & 148.9062 & 2.49 & \\
\hline \multirow{3}{*}{4} & OS-4-1 & 137.6229 & 141.5727 & 2.87 & \multirow{3}{*}{2.75} \\
\hline & OS-4-2 & 139.3990 & 143.5113 & 2.95 & \\
\hline & OS-4-3 & 145.2748 & 148.8195 & 2.44 & \\
\hline \multirow{3}{*}{8} & OS-5-1 & 138.0036 & 142.5931 & 3.33 & \multirow{3}{*}{3.20} \\
\hline & OS-5-2 & 146.2784 & 151.6432 & 3.67 & \\
\hline & OS-5-3 & 135.9549 & 139.5099 & 2.61 & \\
\hline \multirow{3}{*}{16} & OS-6-1 & 138.2125 & 143.9026 & 4.12 & \multirow{3}{*}{4.20} \\
\hline & OS-6-2 & 139.4651 & 145.5730 & 4.38 & \\
\hline & OS-6-3 & 142.9672 & 148.8533 & 4.12 & \\
\hline \multirow{3}{*}{24} & OS-7-1 & 134.2431 & 139.8679 & 4.19 & \multirow{3}{*}{4.26} \\
\hline & OS-7-2 & 147.3052 & 153.5951 & 4.27 & \\
\hline & OS-7-3 & 141.9107 & 148.0412 & 4.32 & \\
\hline \multirow{3}{*}{48} & OS-8-1 & 138.8485 & 141.8060 & 2.13 & \multirow{3}{*}{2.27} \\
\hline & OS-8-2 & 135.6381 & 139.3410 & 2.73 & \\
\hline & OS-8-3 & 140.9224 & 143.6704 & 1.95 & \\
\hline
\end{tabular}

shown in Figure 5. After the designed freeze-thaw cycles were completed, the mass variation of tested oil shale samples will be weighted and recorded. The ultrasonic detection and uniaxial compression experiments were conducted once the weight of oil shale samples has been measured. Overall, the oil shale samples were continuously tested under conditions of periodic freeze-thaw cycles until all the experiments were entirely completed. The flow diagram of the periodic freeze-thaw experiments is shown in Figure 6.

3.4. Uniaxial Compression Test on Oil Shale Samples after Periodic Freeze-Thaw Cycles. Once the oil shale samples were processed under conditions of periodic freeze-thaw cycles, the mechanical properties were measured with the uniaxial compression experiments in the rock mechanics laboratory (locates in the College of Construction Engineering, Jilin University). Under average ambient temperature conditions, the experiments were carried out using a DNS100 microcomputer-controlled electronic universal testing machine, and the strain and stress measurement were acquired with the electric resistance strain gauge. Meanwhile, the axial loading rate was controlled and assigned to $0.5 \mathrm{MPa} / \mathrm{s}$ in all experiments. The process used for testing the mechanical properties of the measured oil shale samples is shown in Figure 7.

3.5. Ultrasonic Detection on Oil Shale Samples after Periodic Freeze-Thaw Cycles. In order to investigate the influence of periodic freeze-thaw cycles on the deterioration characteristics of measured oil shale samples, the ultrasonic propagation velocity of measured sample has been obtained by ultrasonic detection on frozen-thawed samples, as shown in Figure 8. The ultrasonic propagation velocity is varying with various materials, which is highly related to the density of measured samples. While the fractures inside the oil shale samples are extended by internal stress derived from periodically freezing and thawing, the density of oil shale samples is changed. Besides, the nondestructive and ultrasonic longitudinal wave tests on oil shale samples have been completed after various freeze-thaw cycles, and the effect of periodic freeze-thaw cycles on longitudinal wave velocity of oil shale samples was subsequently analyzed and recorded.

\section{Results and Discussions}

4.1. Influence of Periodic Freeze-Thaw Cycles on the Mass Changes of Oil Shale Sample. The mass variation of the measured samples before and after different periodic freeze-thaw cycles has been shown in Table 3. Test results have shown that the mass of each measured sample is increasing after periodic freeze-thaw cycles, and the sample in serial number of OS-6-2 has the maximum mass changes, which goes up to $4.38 \%$. It can be implied that the internal micropore of measured sample is increasing, and the new micropore inside the oil shale appears due to the effect of frost heaving and melt shrinkage. Thereby, the water migrated into the internal 

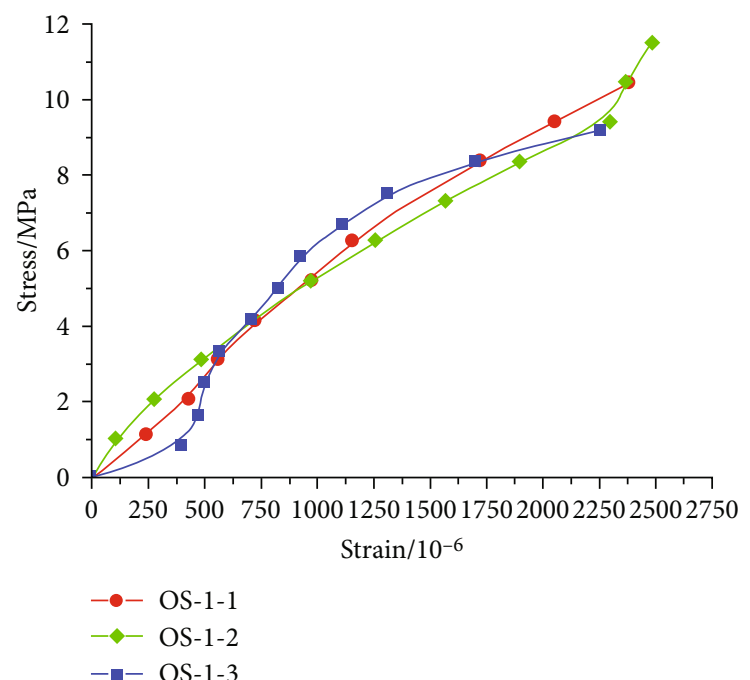

(a) Obtained stress-strain of dry rock sample

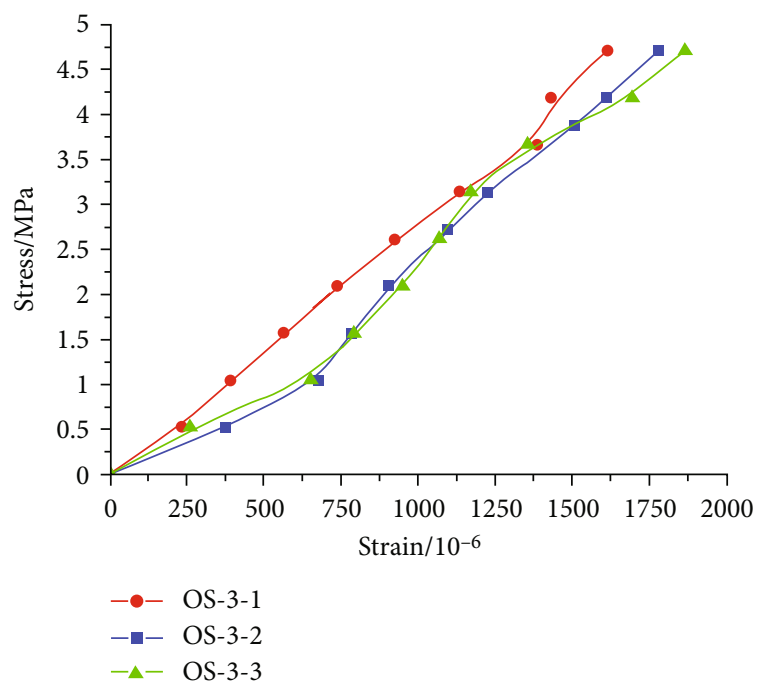

(c) Stress-strain under 2 times of freeze-thaw cycle

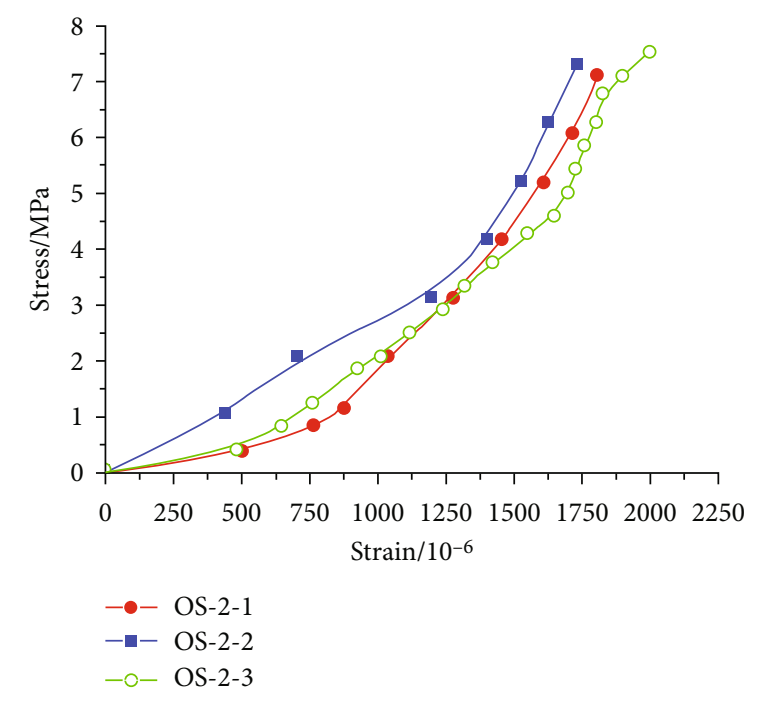

(b) Obtained stress-strain of saturated rock sample

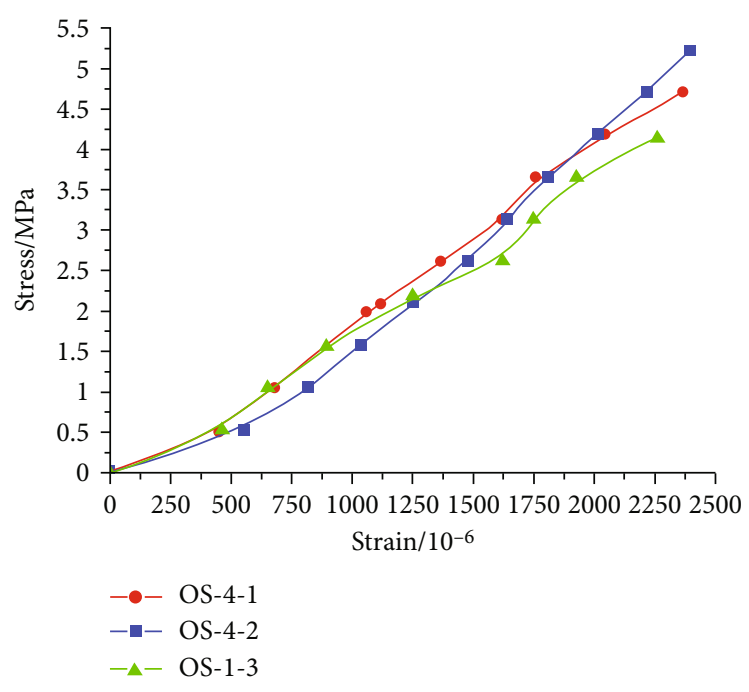

(d) Stress-strain under 4 times of freeze-thaw cycle

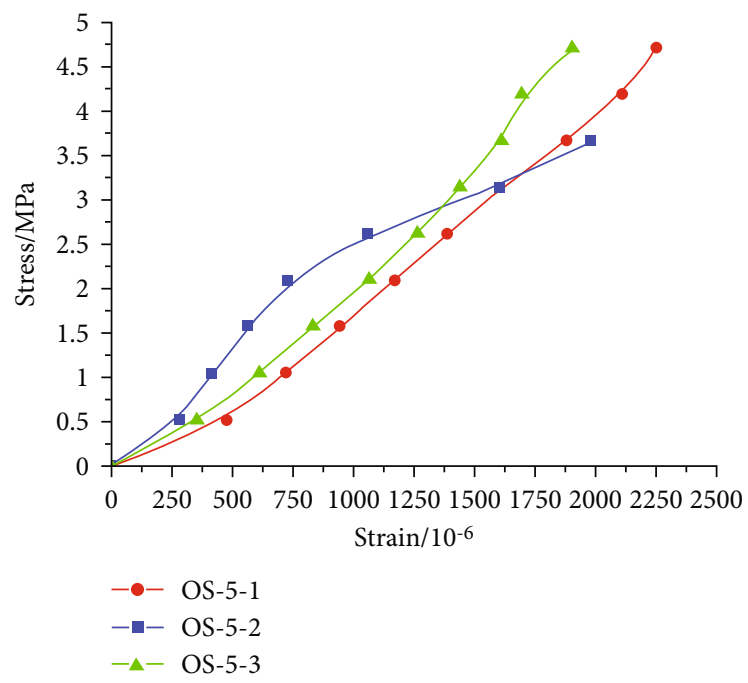

(e) Stress-strain under 8 times of freeze-thaw cycle

FIgure 9: Continued. 


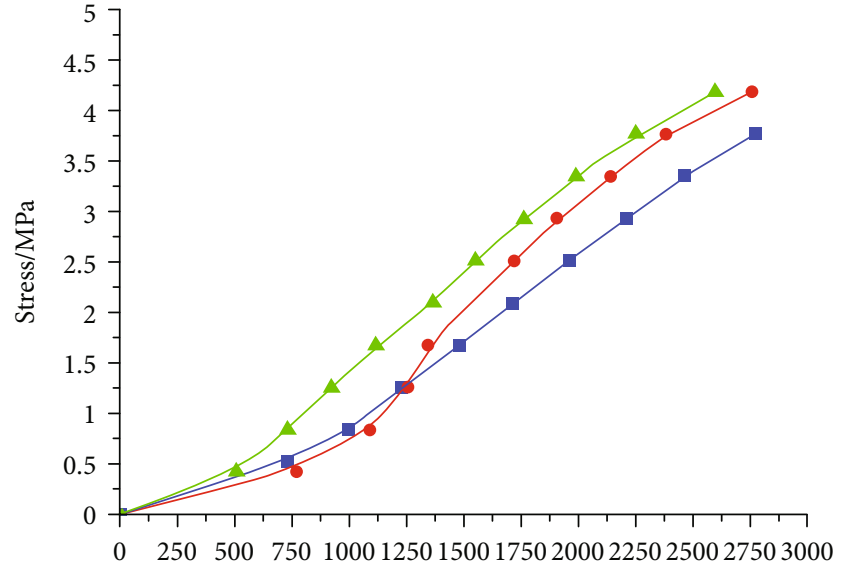

Strain/10-6

$$
\begin{array}{ll}
-\bullet- & \text { OS-6-1 } \\
-\square- & \text { OS-6-2 } \\
-\triangle- & \text { OS-6-3 }
\end{array}
$$

(f) Stress-strain under 16 times of freeze-thaw cycle

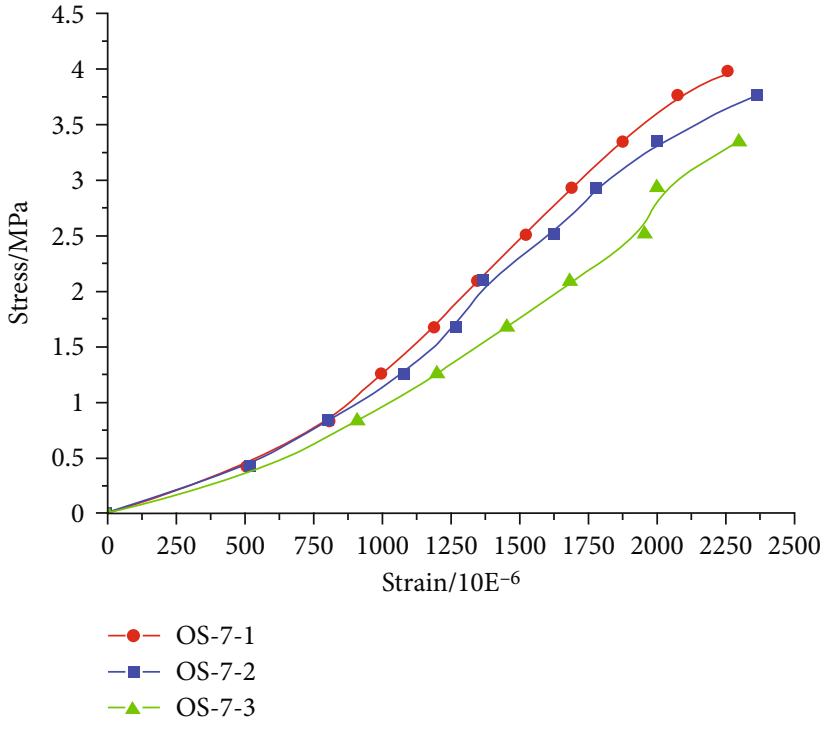

(g) Stress-strain under 24 times of freeze-thaw cycle

Figure 9: Variation of freeze-thaw cycles on the stress and strain of the measured oil shale samples.

TABLe 4: Relationship between the freeze-thaw coefficient and freeze-thaw cycles.

\begin{tabular}{|c|c|c|c|c|c|c|c|}
\hline & Fresh and dry & Fresh and saturated & 2 cycles & 4 cycles & 8 cycles & 16 cycles & 24 cycles \\
\hline Average uniaxial compressive strength $(\mathrm{MPa})$ & 10.3941 & 7.3274 & 4.7087 & 4.6953 & 4.3599 & 4.0460 & 3.6972 \\
\hline Average elastic modulus (GPa) & 4.3710 & 3.9822 & 2.6942 & 2.1367 & 2.0031 & 1.6045 & 1.4961 \\
\hline
\end{tabular}

\begin{tabular}{lccccccc}
\hline & Fresh and dry & Fresh and saturated & 2 cycles & 4 cycles & 8 cycles & 16 cycles & 24 cycles \\
\hline Freeze-thaw coefficient & - & 1 & 0.64 & 0.64 & 0.60 & 0.55 & 0.50 \\
\hline
\end{tabular}

TABLE 5: Relationship among uniaxial compressive strength, elastic modulus, and freeze-thaw cycles.

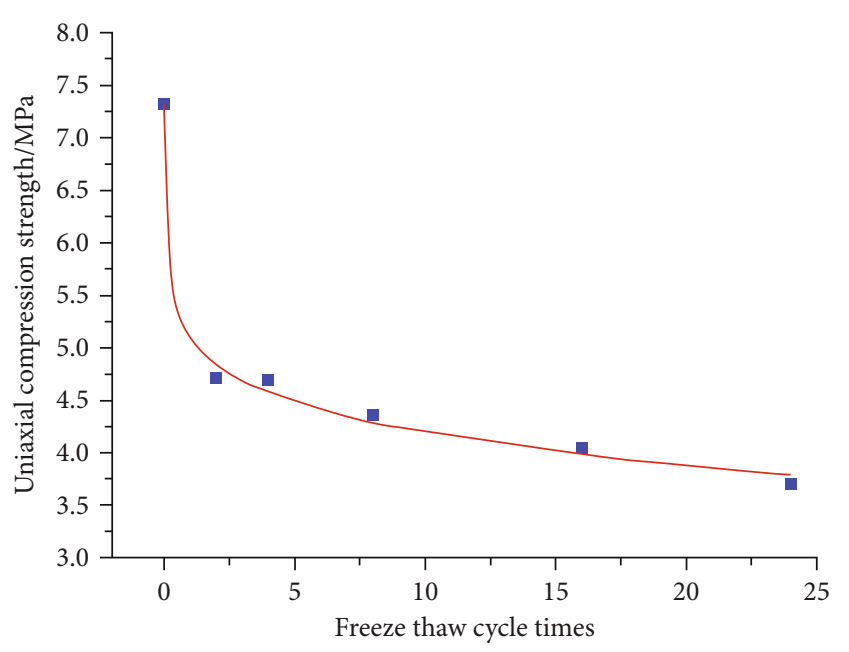

- Experimental data Fitting data

Figure 10: Variation of freeze-thaw cycles on the uniaxial compressive strength of oil shale samples. rock fractures, which resulted in the mass increase of oil shale samples. In addition, the average mass change rate of each group of oil shale samples is increasing while the periodic freeze-thaw cycles are less than 24 . However, the average mass change rate of measured samples will slightly decline with the increase of periodic freeze-thaw cycles while the freeze-thaw cycle is more than 24 . It can be indicated that the expansion of micropore is hindered and the fractures inside the oil shale samples are squeezed; thus, it is difficult for moisture to come into the fractures inside the oil shale samples.

In essence, the volume of fissure water occupied in the rock matrix or the external water enters through the rock fractures will increase by approximately $9 \%$ after the ice is frozen. Besides, the ice exerts pressure on both sides of the cracks, leading to the increase of depth and width of cracks. While the ice is melting, generated water will flow into the new cracks. The water will be refrozen when the temperature drops, which enlarges the internal cracks inside the oil shale samples. Therefore, the periodic freeze-thaw cycle will weaken the oil shale samples until it is completely destroyed.

4.2. Influence of Periodic Freeze-Thaw Cycles on the StressStrain of Oil Shale Samples. As shown in Figure 9, the 


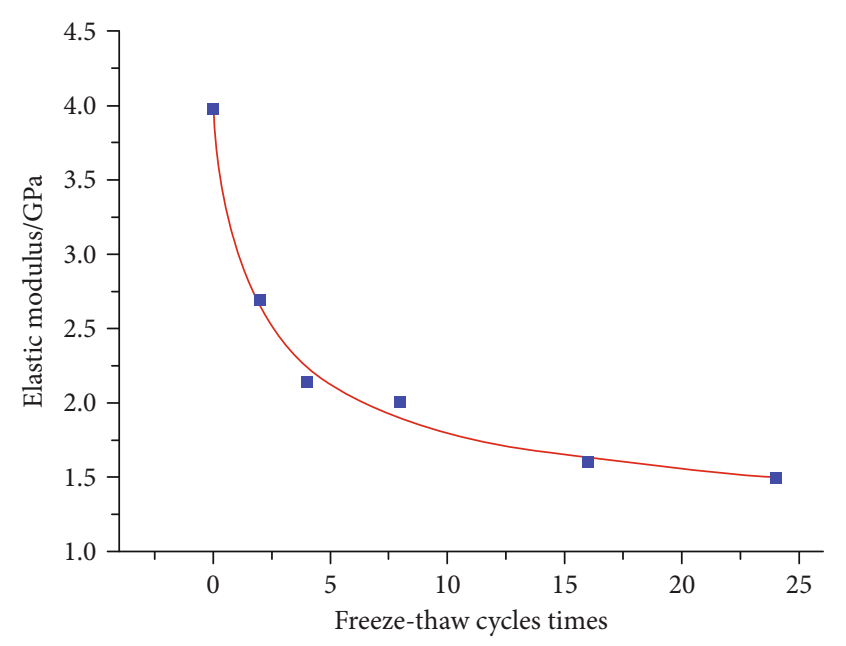

- Experimental data

- Fitting data

Figure 11: Elastic modulus of oil shale sample varies with the number of freeze-thaw cycles.

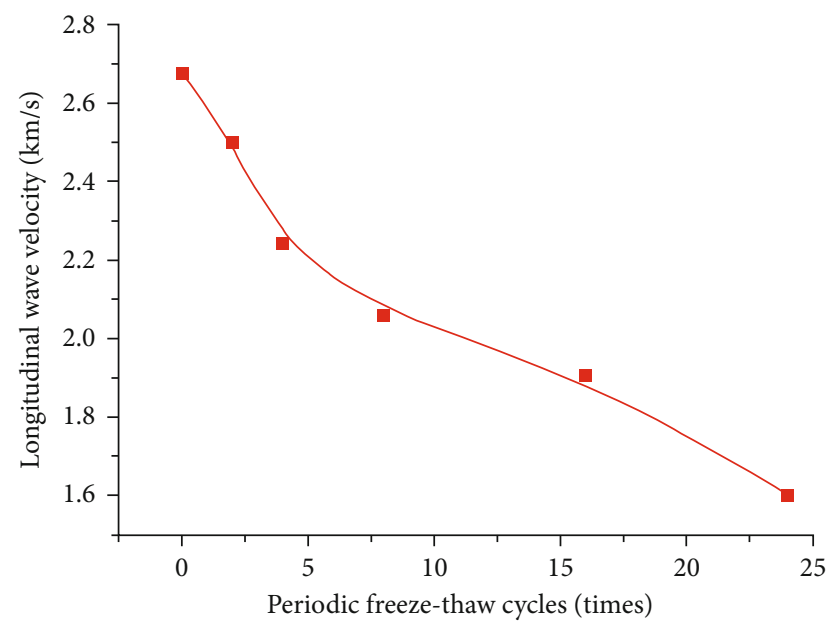

FIGURE 12: Longitudinal wave velocity of oil shale sample varies with periodic freeze-thaw cycles.

stress-strain curves of all the tested oil shale samples were obtained based on the test results of uniaxial compressive strength after various periodic freeze-thaw cycles. The stress and strain of the dry rock samples, saturated samples, and measured samples were obtained and checked. In addition, Young's modulus of the oil samples was determined by the ratio of compression stress and longitudinal strain; hence, the compression stress and longitudinal strain of all samples should be precisely confirmed. Moreover, all tested results about periodic freeze-thaw experiments should be repeatedly measured for 3 times in order to reduce the measurement uncertainty.

It can be inferred that the damage and deterioration on the mechanical properties of the oil shale samples can be influenced by the periodic freeze-thaw cycles. Due to the hardness of the oil shale samples being low, excessive fractures are present inside the oil shale samples; thus, the stress-strain variation on the oil samples is determined by the freeze-thaw cycles. When the number of freeze-thaw cycles is 48 , the deterioration on the mechanical properties of the oil shale sample is the greatest. Although individual differences of the oil shale samples result in diverse effects on the stress-strain of tested samples, the deterioration of the oil shale samples can be illustrated by the obtained stress-strain.

Under the effect of periodic freeze-thaw cycles, there is an obvious drop in uniaxial compressive strength, and the downtrend is also obvious, especially in the initial cycles of the freeze-thaw process. Comparing the stress-strain changes of oil shale samples before and after the periodic freeze-thaw process, a similar variation tendency can be found throughout the periodic freeze-thaw process, which can be divided into three stages: the pressure stage, elastic deformation stage, and the crack extension stage.

4.3. Influence of Freeze-Thaw Cycles on the Freeze-Thaw Coefficient of Oil Shale Samples. The rock's ability to resist freeze-thaw damage and deterioration can be expressed by the freeze-thaw coefficient. According to the specifications for rock tests in water conservancy and hydroelectric engineering (SL264-2001), the formula of the rock freezethawing coefficient is shown as follows:

$$
K_{f}=\frac{\overline{R_{f}}}{\overline{R_{s}}},
$$

where $K_{f}$ is the freeze-thaw coefficient, $\overline{R_{f}}$ is the saturated uniaxial compressive strength after freeze-thaw test (MPa), and $\overline{R_{s}}$ is the saturated uniaxial compressive strength before the periodic freeze-thaw tests (MPa). The freeze-thaw coefficients of the tested oil shale samples are shown in Table 4.

According to the measured results in Table 4, the freezethaw coefficient of oil shale samples significantly reduces with the increased number of freeze-thaw cycles. In the first 2 freeze-thaw cycles, the freeze-thaw coefficient of the tested samples rapidly decreases. Subsequently, the freeze-thaw coefficient of the samples continues to decrease. However, the decreasing rate of the freeze-thaw coefficient significantly reduces after the initial 2 freeze-thaw cycles. It can be inferred that the pore space inside the oil shale sample has been gradually reduced, and the sample will be compacted during the freeze-thaw process; thus, the freeze-thaw coefficient of oil shale samples decreases.

4.4. Variation of the Uniaxial Compressive Strength and Elastic Modulus. As shown in Table 5, the average uniaxial compressive strength and elastic modulus are reduced with the increased number of freeze-thaw cycles, and the maximum compressive strength and elastic modulus are obtained from the fresh and dry oil shale samples. Due to the pore matrix of oil shale samples is connected by rock particles, the fresh and dry oil shale samples have little moisture inside the pore volume, causing the compressive strength and elastic modulus of oil shale samples to be maximized, which reach up to $10.39 \mathrm{MPa}$ and $4.37 \mathrm{GPa}$, respectively. Once the 
TABLE 6: Relationship between longitudinal wave velocity and freeze-thaw cycles.

\begin{tabular}{|c|c|c|c|c|c|c|c|}
\hline Freeze-thaw cycle & Dry & 0 times & 2 times & 4 times & 8 times & 16 times & 24 times \\
\hline Average longitudinal wave velocity $(\mathrm{km} / \mathrm{s})$ & 2.4644 & 2.6751 & 2.4 .991 & 2.2418 & 2.0581 & 1.9055 & 1.6025 \\
\hline
\end{tabular}

tested oil shale samples have been processed by several periodic freeze-thaw cycles, the compressive strength and elastic modulus of oil shale samples gradually decrease. It can be inferred that the water inside the pore volume is periodically frozen and melted; thereby, the connection between rock particles has been broken by the interaction force of rock particles, which results in the reduction of the average compressive strength and elastic modulus. The tested oil shale samples processed with 24 periodic freeze-thaw cycles exhibited the minimum compressive strength and elastic modulus among all the tested oil shale samples, which is simply 3.69 $\mathrm{MPa}$ and $1.49 \mathrm{GPa}$, respectively.

Meanwhile, the uniaxial compressive strength of the oil shale sample varied closely with the numbers of freezethaw cycles. As shown in Figure 10, the uniaxial compressive strength of oil shale is greatly influenced by the periodic freeze-thaw cycles. It can be implied that the uniaxial compressive strength of the oil shale sample exponentially decreased with the increased number of freeze-thaw cycles. In the first 2 freeze-thaw cycles, the uniaxial compressive strength dramatically decreased; then, the amplitude reduces, and eventually, the uniaxial compressive strength was only slightly decreasing with the remaining freeze-thaw cycles. After the oil shale samples have undergone 24 freeze-thaw cycles, the maximum variation rate of uniaxial compressive strength was reached up to $64 \%$.

According to the experimental results, the relationship between the uniaxial compressive strength and the number of freeze-thaw cycles can be fitted

$$
\sigma=-\frac{19.82058+27.14498}{(1+n E 0.15905 / 11.09104)}
$$

where $\sigma$ is the uniaxial compressive strength (MPa), $n$ is the number of freeze-thaw cycles, and the correlation coefficient is 0.98587 .

Additionally, the elastic modulus of the tested oil shale sample was obtained under conditions of different freezethaw cycles. As shown in Figure 11, the elastic modulus of the oil shale sample exponentially decreased with the increasing of freeze-thaw cycles, and the maximum elastic modulus was approximately $4 \mathrm{GPa}$, whereas the minimum elastic modulus of tested oil shale sample is approximately $1.5 \mathrm{GPa}$. After processing the oil shale samples with 24 freeze-thaw cycles, the maximum variation rate of the elastic modulus reached up to $65 \%$, which is greatly influenced and determined by the number of freeze-thaw cycles.

According to the obtained elastic modulus results, the relationship between the elastic modulus and freeze-thaw cycles can be fitted as

$$
E=\frac{1.14961+2.83426}{\left(1+n^{0.82524 / 1.99395}\right)}
$$

where $E$ is the elastic modulus (GPa), $n$ is the number of freeze-thaw cycles, and the correlation coefficient is 0.98423 .

4.5. Influence of Freeze-Thaw Cycles on Longitudinal Wave Velocity of Oil Shale Samples. According to the obtained wave velocity of tested oil shale sample, the longitudinal wave velocity of processed oil shale sample is shown in Figure 12. With the increase of periodic freeze-thaw cycles, the longitudinal wave velocity of oil shale sample dramatically decreases. The periodic freeze-thaw cycle has a significant influence on the longitudinal wave velocity of tested oil shale samples. As shown in Table 6, once the oil shale samples have been proceeded with 24 periodic freeze-thaw cycles, the minimum wave velocity of $1602 \mathrm{~m} / \mathrm{s}$ can be accomplished.

Due to the performance of periodic freeze-thaw cycles on measured oil shale sample, the frozen ice particles inside the fractures will be melted while the temperature rises; otherwise, the water or moisture will be repeatedly frozen, which enlarges the fractures inside the oil shale samples. Thereby, the density of oil shale sample is decreasing due to the pore volume of the measured sample being increased. However, the wave velocity positively varies with the density of measured materials; thus, the longitudinal wave velocity reduces with the increase of periodic freeze-thaw cycles.

\section{Conclusions}

Under conditions of periodic freeze-thaw cycles, the physical and mechanical properties of oil shale samples were dramatically varied, and related conclusions and findings can be obtained:

(1) Periodic freeze-thaw cycles greatly influence the physical and mechanical properties of oil shale samples. Once the oil shale samples were frozen and thawed for 24 cycles, the maximum compressive strength and elastic modulus were $10.39 \mathrm{MPa}$ and $4.37 \mathrm{GPa}$, respectively, besides the maximum variation rates of uniaxial compressive strength and elastic modulus reaches up to $64 \%$ and $65 \%$, respectively

(2) The freeze-thaw coefficient of measured oil shale samples exponentially decreased with the increased number of freeze-thaw cycles, whereas the longitudinal wave velocity of tested samples ranged from $1602 \mathrm{~m} / \mathrm{s}$ to $2464 \mathrm{~m} / \mathrm{s}$, as a result of the new micropores inside the oil shale sample

\section{Data Availability}

The data used to support the findings of this study are included within the article. 


\section{Conflicts of Interest}

No conflict of interest exits in the submission of this manuscript.

\section{Authors' Contributions}

The manuscript is approved by all authors for publication.

\section{Acknowledgments}

This study was supported by the Fundamental Research Funds for the Central Universities(Project No. 2021CDJQY-028 and No.2019CDXYZH0019), the Natural Science Foundation of Chongqing Province, China (Grant No. cstc2019jcyjmsxmX0633), and the Special Project funded by Chongqing Postdoctoral Science Foundation (Project No. Xm2017068).

\section{References}

[1] M. L. SJMK and H. M. Boak, "Panel discussion on the state of the U.S. and global oil shale development: introductory comments," in 32nd Oil Shale Symposium Golden, p. 53, Curran Associates, Inc, Colorado, USA, 2012.

[2] L. I. Shuyuan, X. Tang, H. Jilai, and Q. Jiashan, "Global oil shale development and utilization today-two oil shale symposiums held in 2012," Sino-Globle Energy, vol. 1, pp. 3-11, 2013.

[3] C. H. A. I. N. SSL, Case study of oil shale production, Universiti Tunku Abdul Rahman, 2016.

[4] X. Zhang, S. Zhang, Y. Luo, and D. Wu, "Experimental study and analysis on a fluidic hammer-an innovative rotary- percussion drilling tool," Journal of Petroleum Science and Engineering, vol. 173, pp. 362-370, 2019.

[5] L. Jian and L. Weiguo, "Problems and environmental impacts induced by mining technology of shale oil and gas and coalbed methane," Science Technology and Engineering, vol. 17, no. 30, pp. 121-134, 2017.

[6] Z. Chuanwen, M. Qingqiang, and T. Xuan, "Present situation and prospect of oil shale mining technology," Mineral Exploration, vol. 12, no. 8, pp. 1798-1805, 2021.

[7] E. Elmer, Method and apparatus for the destructive of kerogen in situ: US, 5058675, U.S. Patent and Trademark Office, 1991.

[8] S. L. Wellington, I. E. Berchenko, E. P. De Rouffignac et al., In situ thermal processing of an oil shale formation to produce a condensate: US6, 923, 257.2005-8-2, 2005.

[9] J. M. D. R. Karanikas, In-situ thermal processing of an oil shale formation while inhibiting coking, 2005.

[10] Z. Jinxun, Y. Qi, H. Yang, and S. Yongwei, “Temperature field expansion of basin-shaped freezing technology in sandy pebble stratum of Beijing," Rock and Soil Mechanics, vol. 41, no. 8, pp. 2796-2807, 2020.

[11] M. Josh, L. Esteban, C. Delle Piane, J. Sarout, D. N. Dewhurst, and M. B. Clennell, "Laboratory characterisation of shale properties," Journal of Petroleum Science and Engineering, vol. 88-89, pp. 107-124, 2012.

[12] S. Youhong, W. Guo, and S. Deng, "The status and development trend of in-situ conversion and drilling exploitation technology for oil shale," Drilling Engineering, vol. 48, no. 1, pp. 57-67, 2021.

[13] U. Smoltczyk, Geotechnical Engineering Handbook, Volume 2: Procedures, John Wiley \& Sons, 2003.
[14] Z. Bo, W. Yang, and B. Wang, "Plastic design theory of frozen wall thickness in an ultradeep soil layer considering large deformation characteristics," Mathematical Problems in Engineering, vol. 2018, Article ID 8513413, 2018.

[15] Li, Experimental Study on the Influence of Freezing Wall on Groundwater Temperature Field and Flow Field during Oil Shale In-Situ Mining, Jilin University, 2020.

[16] A. Momeni, Y. Abdilor, G. R. Khanlari, M. Heidari, and A. A. Sepahi, "The effect of freeze-thaw cycles on physical and mechanical properties of granitoid hard rocks," Bulletin of Engineering Geology and the Environment, vol. 75, no. 4, pp. 1649-1656, 2015.

[17] L. M. Del Roa, F. Lopez, F. J. Esteban et al., "Ultrasonic study of alteration processes in granites caused by freezing and thawing," in IEEE Ultrasonics Symposium, 2005, pp. 415-418, Rotterdam, Netherlands, 2005.

[18] H. Yavuz, "Effect of free e-thaw and thermal shock weathering on thephysical and mechanical properties of an andesite stone," Bulletin of Engineering Geology and the Environment, vol. 70, no. 2, pp. 187-192, 2011.

[19] Z. Q. P. Y. Yang Gengshe, "On the microdamage characteristics of rock under the frost and thaw conditions," Journal of Xi'an University of Science and Technology, vol. 139, 2003.

[20] Z. Q. P. Y. Yang Gengshe, "CT scanning test of meso-damage propagation of rock under different freezing temperature," Journal of Chang'an University (Natural Science Edition), vol. 24, no. 6, pp. 40-46, 2004.

[21] Z. Q. R. J. Yang Gengshe, "Study on the effect of freezing rate on the damage CT values of Tongchuan sandstone," Chinese journal of rock mechanics and engineering, vol. 23, no. 24, pp. 4099-4104, 2004.

[22] Y. Yang, D. Lei, H. Cai, S. Wang, and Y. Mu, "Analysis of moisture and temperature fields coupling process in freezing shaft," Thermal Science, vol. 23, no. 3 Part A, pp. 1329-1335, 2019.

[23] H. G. Z. J. Wu Gang, "Experimental study on cycles of freezethaw of marble," Chinese Journal of Rock Mechanics and Engineering, vol. 25, pp. 2930-2938, 2006.

[24] H. M. W. S. Liu Chengyu, "Experimental investigation on freeze-thawing damage characteristics of granite at low temperature," Journal of Hunan University of Science \& Technology: Natural Science Edition, vol. 20, no. 1, pp. 37-40, 2005.

[25] M. Bellanger, "HFR (1993) water behavior in limestone as a function of pores structure:application to frost resistance of some lorraine limestones," Engineering Geology, vol. 36, no. 1-2, pp. 99-108, 1993.

[26] J. Haibin, Theoretical Damage Models of Porous Rocks and Hard Jointed Rocks Subjected to Frost Action and Further Experimental Verifications, China University of Geosciences, Wuhan, 2016.

[27] J. Li, Experiment study on deterioration mechanism of rock under the conditions of freezing-thawing cycles in cold regions based on NMR technology, Central South University, 2012.

[28] Q. W. X. P. Tong Cong, "Progress of theoretical research of rock damage," Copper Engineering, vol. 7, 2011.

[29] L. Q. Xu Guangmiao, "Analysis of mechanism of rock failure due to freeze thaw cycling and mechanical testing study of frozen-thawed rocks," Chinese Journal of Rock Mechanics and Engineering, vol. 24, no. 17, pp. 3076-3082, 2005.

[30] Q. Wang, Experiment on thermal and electrical physical properties of oil shale in Jinlin Huadian area, Jilin University, 2011. 